\title{
Politik mit Gesundheitsfolgen
}

\section{Yvonne Gilli}

Dr. med., Präsidentin der FMH

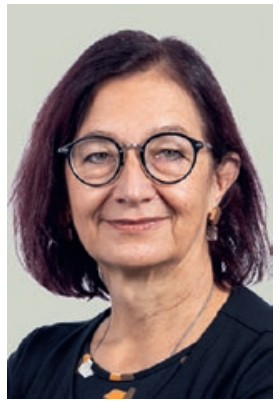

Viele Menschen spüren in der Corona-Krise erstmals, dass die nationale Gesundheitspolitik nicht einfach abstrakte Themen im fernen Bern betrifft, sondern sich unmittelbar auf ihre eigene Gesundheit auswirkt: Von ihr hängt ab, ob man eine Impfung erhält oder nicht.

Verständlich also, dass in der am 19. März abgeschlossenen Frühjahrssession vor allem die impfpolitischen Fragestellungen Beachtung fanden. Insbesondere die Impfstoffbeschaffung stand in der Kritik. Trotz aller Lieferverzögerungen und ausstehenden Zulassungen bekräftigte der Bundesrat das Ziel, bis Ende Juni alle Impfwilligen zu impfen [1]. Dieses Versprechen sollen andere einlösen, nämlich Kantone und Ärzteschaft. Die erhalten ihre Impfdosen zwar später, sollen sie aber trotzdem bis zum gleichen Termin - und die Arztpraxen auch ohne kostendeckende Vergütung - verimpfen.

Die Folgen des ersten Kostendämpfungspakets könnten uns noch deutlich länger beschäftigen als die Corona-Krise.

Durch den Fokus auf das Corona-Geschehen erhielten andere gesundheitspolitische Geschäfte des Parlaments leider weniger bis gar keine Aufmerksamkeit, wie z.B. die Entscheidungen zum ersten Kostendämpfungspaket. Mit ihnen begann ein politischer Prozess, dessen Folgen uns noch deutlich länger beschäftigen könnten als die Corona-Krise.

Weitgehend unbemerkt von der Öffentlichkeit entschied das Parlament, dass zukünftig zwei unterschiedliche Tarifstrukturen für die gleichen Leistungen existieren sollen: eine für Einzelleistungstarife und eine für Pauschalen. Das Kostendämpfungspotenzial ambulanter Pauschalen wurde damit ohne Not verschenkt, denn eine eigene Kostenbasis für Pauschaltarife verursacht Fehlanreize und finanziert teure Spitalinfrastrukturen, wo die ambulante Arztpraxis völlig ausreichen würde. Den Anstrengungen für eine einheitliche Tarifstruktur für alle ambulanten Leistungen in der Schweiz - einschliesslich Pauschalen - bleibt als einziger Lichtblick, dass wenigstens weiterhin freiwillige Pauschalen vereinbart werden können.
Der Experimentierartikel konnte leider nicht wie geplant mit dem Sessionsende abgeschlossen werden. Nach hartem Ringen blieb unter anderem offen, ob Experimente ausschliesslich gesetzlich vordefinierten Kostendämpfungsthemen gelten dürfen - oder ob auch die Förderung von Digitalisierung und Qualität Zweck der Experimente sein dürfte. Dies wird voraussichtlich im Sommer entschieden.

Während sich einige Geschäfte bereits dem Ende nähern, steht das für die Gesundheitsversorgung weitreichendste Geschäft des ersten Kostendämpfungspakets noch am Anfang: die «Massnahmen zur Steuerung der Kosten", mit denen der Bundesrat die Tarifpartner verpflichten möchte, die für ein Kalenderjahr «gerechtfertigten» Kosten im Voraus festzulegen - und finanzielle Sanktionen für das Überschreiten dieser Kostengrenze vorzusehen. Dieser Artikel 47c KVG wurde bei seiner ersten Beratung im Oktober 2020 durch den Nationalrat knapp abgelehnt. Im April wird nun die ständerätliche Gesundheitskommission erstmals über diesen vom EDI eingebrachten Vorschlag beraten.

Die gemäss Artikel 47c festzulegende Kostenobergrenze würde nicht nur medizinische Leistungen beschränken und unserem Gesundheitswesen noch mehr Administration bescheren. Sie widerspricht auch der Bundesverfassung, wie ein Gutachten des Sozialrechtsexperten Prof. Kieser belegt: Die Grundversicherung sichert dem Versicherten im Krankheitsfall vorab definierte Leistungen zu. Es widerspräche dem Versicherungsprinzip, die beanspruchbaren Leistungen im Nachhinein zu begrenzen.

\section{Eine neu festzulegende Kostenobergrenze} würde nicht nur medizinische Leistungen beschränken - sie wäre auch verfassungswidrig.

Es bleibt zu hoffen, dass diese Argumente in der Politik Gehör finden werden. Denn sonst könnten wir auch hier spüren, wie sich gesundheitspolitische Entscheidungen unmittelbar auf die Gesundheit auswirken und darüber mitentscheiden, ob jemand eine Behandlung erhält oder nicht.

1 Fragestunde vom 15. März 2021. Frage 21.7261 Bregy und Frage 21.7288 Schneeberger. 